\title{
ARQUITETURA PRISIONAL E OS DIREITOS SOCIAIS NO SISTEMA PENITENCIÁRIO
}

\author{
Érika Wen Yih Sun
}

\begin{abstract}
Resumo
Este artigo aborda a interferência da arquitetura prisional sobre os direitos sociais no sistema penitenciário. À luz da legislação concernente à execução penal, o sujeito encarcerado deveria ser privado tão somente da liberdade, mas, diante da realidade do sistema, acaba vendo mitigados seus direitos sociais, como a alimentação, o trabalho, a saúde, a educação, dentre outros. Neste estudo, o objetivo principal é observar o desempenho dos estabelecimentos na garantia dos direitos sociais, fazendo, para tanto, uma análise dos aspectos arquitetônicos utilizados no planejamento espacial das prisões, de modo a verificar as associações possíveis entre as intenções iniciais de projeto e os efeitos alcançados na realidade, bem como as variações na edificação pós-ocupação. A hipótese levantada é que tais direitos não precisam ser eliminados, sob qualquer fundamento, podendo ser plenamente usufruídos no sistema penitenciário, desde que sejam aplicadas políticas públicas adequadas.
\end{abstract}

Palavras-chave: Direitos sociais, política social, arquitetura prisional.

\begin{abstract}
The main purpose of this article is to verify the influences that the penitentiary architecture has on social rights in the penitentiary system. According to the law, the prisoner should only be devoid from his freedom, but, actually, he sees himself mitigated from most of his social rights, as food, work, health, education, among others. This text describes an analysis of this kind of buildings performance in its purposes of guaranteeing the social rights, by observing the architectonic aspects used during the prison space planning, so that it is possible to verify the associations between the first intentions of the project and its reached effects, as the modifications after use. This study shows that those rights do not need to be eliminated, under any circumstance or reason, and they are possible in such context if appropriate public policies are applied.
\end{abstract}

Keywords: Social rights, social policies, penitentiary architecture. 


\section{DIREITOS SOCIAIS}

Os direitos sociais, em um entendimento mais global e generalizado, poderiam ser definidos como um conjunto de necessidades humanas compartilhadas e, portanto, sociais, cuja obrigação de resguardar é atribuída ao Estado. O conceito de necessidades humanas, portanto, é relevante para justificar os direitos de cidadania em geral, e os direitos sociais em particular ${ }^{1}$.

Preliminarmente, é de fundamental importância que se faça uma delimitação dessas necessidades humanas básicas, que levam à criação de tais direitos sociais. Para tanto, cabe ressaltar o entendimento de que não há uma necessidade (individual), mas necessidades (sociais), que levam a existir relações entre indivíduos que se tornam sujeitos quando entram em relação para suprir necessidades comuns ${ }^{2}$. Assim, é necessário distinguir necessidades humanas básicas de carências meramente materiais.

Em seguida, pode-se identificar dois tipos de necessidades básicas, sendo que uma se refere à sobrevivência física, precondição essencial da existência animal, e outra, à autonomia, que tem ligação tanto à possibilidade de ação livre de constrangimentos quanto à critica, que permite que as pessoas avaliem e modifiquem regras e práticas da cultura a que pertencem ${ }^{3}$.

Diante de tais considerações, o sentido de justiça ou injustiça passa a referir-se ao modo como agem as instituições públicas em relação à distribuição das desigualdades. Desta forma, o Estado fica incumbido de prover bens e serviços sociais em correspondência aos direitos dos cidadãos de terem suas necessidades básicas satisfeitas ${ }^{4}$.

Nestes termos, cabe ao estudo das ações públicas a compreensão da lógica das diferentes formas de intervenção do Estado sobre a sociedade, ao identificar os modos de relação existentes entre atores públicos e privados ${ }^{5}$.

\footnotetext{
${ }^{1}$ Apud PISON, José Martinez de. Políticas de bienestar: un estudio sobre los derechos sociales. Madrid: Tecnos, 1998.

${ }^{2}$ Apud BRAGE, Luis Ballester. Las necesidades sociales: teorías y conceptos básicos. Madrid: Sintesis, 1999.

${ }^{3}$ PEREIRA, Potyara A.P. Políticas públicas e necessidades humanas com enfoque no gênero. MIMEO.

${ }^{4}$ PEREIRA, Potyara A.P. Ibid.

${ }^{5}$ MULLER, Pierre \& SUREL, Yves. L'Analyse des politiques publiques. Paris: Editions Montchrestien, 1998.
} 


\title{
A PRIVAÇÃO DOS DIREITOS SOCIAIS NO CONTEXTO CAPITALISTA
}

No contexto de sociedade capitalista, a produção funciona à base da espoliação legalizada da maioria pela minoria, sendo impossível atender às "necessidades" daquela, que extrapolam os direitos sociais. Como resultado,

\begin{abstract}
cria-se um sistema de "deuses" que podem "ter tudo", com os quais a plebe é convocada a se identificar. Mostrando como alguns desperdiçam no luxo o que retiram dos que trabalham e que faz falta à família destes, quer-se provocar admiração com o que poderia excitar inveja e rancor. Ainda que a massa seja idiota a ponto de aceitar isso, gera-se ainda mais insatisfação. Uma minoria de pobres opta pela espoliação ilegal de quem tiver algo, e a isso se chama então de crime, enquanto a maioria opta por apostar na vida eterna e na loteria, por consumir drogas ou sonhar com a fama, esperando fazer assim parte da minoria privilegiada ${ }^{6}$.
\end{abstract}

A diferença social gerada pela má distribuição de rendas, que causa um abismo enorme entre as classes mais altas e mais baixas, faz com que o Estado tenha sérias dificuldades em atender as demandas a ele incumbidas. Enquanto algumas camadas da sociedade tem abundância de recursos, outras sofrem de profundas privações. Assim, é necessário analisar criteriosamente as vulnerabilidades sociais para que certos equívocos sejam evitados.

A radicalização das vulnerabilidades sociais costuma provocar na sociedade um sentimento de indignação bastante difuso. (...)

A noção de desumanidade que emerge no imaginário social, diante da visão dos efeitos provocados por estados de privação profunda, quase sempre é identificada a partir de uma "culpa" bifronte: de um lado, a responsabilidade do próprio indivíduo que não se "preparou adequadamente" para a vida - e nesses casos são sempre lembrados que "saíram do nada e deram certo" -, algo tendendo a responsabilizar o miserável pela sua própria condição; e, de outro lado, a cobrança imediata de intervenção do governo para remediar a situação ${ }^{7}$.

\footnotetext{
${ }^{6}$ NIETZSCHE, FRIEDRICH. Fragmentos do Espólio. Brasília: Ed. Universidade de Brasília, 2004. Prefácio de Flávio R. Kothe. p.24.

${ }^{7}$ GOMES JUNIOR, Newton N. Pobreza, desnutrição e segurança alimentar: tentando novo diálogo a partir do conceito de necessidades humanas básicas in Ser Social: Revista do Programa de Pós-Graduação em Política Social / Universidade de Brasília. Departamento de Serviço Social - v.1, n.1 (1 ${ }^{\circ}$ semestre/1998). Brasília, SER Social UnB, 1998.
} 


\section{ÉRIKA WEN YIH SUN}

Desta maneira, na ausência de políticas públicas voltadas para a esfera social, a conseqüência é um verdadeiro caos, sobretudo quando há orientação pelas ideologias neoliberais.

\footnotetext{
O desmonte das redes de proteção social como direito (...) abandonou alargadas parcelas da população - que até então podiam contar com a retaguarda dos serviços sociais de provisão governamentais para garantir-lhes melhores condições de vida do que conseguiram por seus próprios meios - à desproteção quase total que caracteriza a luta pela sobrevivência no espaço do mercado desregulado.

Os resultados dessa orientação podem ser traduzidos pela radicalização de todos os indicadores que medem os níveis de insegurança social na sociedade. Em menos de quatro décadas, o mundo se depara com os piores índices de desemprego, de miséria, de violência e desesperança dos últimos cem anos ${ }^{8}$.
}

Diante de tal realidade, abre-se, de fato, uma grande brecha para o aumento da violência e da criminalidade. A conseqüência mais evidente é a marginalização de indivíduos em decorrência dessas diferenças sociais, o que faz com que se busquem soluções aos problemas que o Estado não consegue sanar por meios próprios. Tal situação faz com que a sociedade seja dividida em dois, tornando-se, assim, dois focos distintos de atenção: um destinado aos cidadãos livres e outro aos cidadãos encarcerados, que vivem no sistema penitenciário.

\section{O CRIME}

É possível fazer uma analogia entre o crime e o tabu, que, segundo Freud, “(...) traz em si um sentido de algo inabordável, sendo principalmente expresso em proibições e restrições ${ }^{9}$ ". Assim, da mesma forma que o termo é aplicado corriqueiramente, o tabu refere-se àquilo que é interditado, reprimido, denotando proibições, restrições, abstinências e renúncias.

\footnotetext{
${ }^{8}$ GOMES JUNIOR, Newton N. Ibid.

${ }^{9}$ FREUD, Sigmund. Totem e Tabu. Rio de Janeiro: Imago, 2005. p.28 
Tudo é proibido, e eles [os povos primitivos] não têm nenhuma idéia por quê e não lhes ocorre levantar a questão. Pelo contrário, submetem-se às proibições como se fossem coisa natural e estão convencidos de que qualquer violação terá automaticamente a mais severa punição.

(...)

Por trás de todas essas proibições parece haver algo como um teoria de que elas são necessárias porque certas pessoas e coisas estão carregadas de um poder perigoso $(\ldots)^{10}$.

Tais proibições dirigem-se principalmente contra a liberdade de prazer, de movimento e de comunicação. Os membros da sociedade, neste sentido, precisariam se abster de certos comportamentos sob o fundamento de que haveria um poder perigoso capaz de trazer uma punição severa. $\mathrm{O}$ tabu, portanto, poderia ser equiparado ao crime, que é definido como um fato típico e antijurídico, dotado de culpabilidade, especificado no ordenamento jurídico. Seria, portanto, um conjunto de comportamentos indizíveis, que deveriam ser evitados a qualquer custo sob o fundamento da segurança jurídica e da manutenção da ordem social.

O tabu, na exposição de Freud, fica sujeito ao deslocamento, isto é, estende-se de um objeto a outro por quaisquer caminhos que o contexto possa proporcionar e esse novo objeto torna-se também impregnado do "poder" emanado. É como se fosse uma espécie de doença contagiosa. Segundo Freud, "esta transmissibilidade do tabu é um reflexo da tendência $(. . .)^{11 \text { ". }}$. Neste sentido, deve-se realizar um ato de expiação e/ou penitência, de modo a suspender os efeitos malignos do tabu, já que

\footnotetext{
(...) a lembrança e a tentação se reúnem novamente. Deve-se admitir também que, na medida em que o exemplo de um homem que transgride uma proibição tenta o outro a fazer o mesmo, a desobediência a proibições se propaga como um contágio, da mesma maneira que um tabu se transfere de uma pessoa para um objeto material e de um objeto material para outro ${ }^{12}$.
}

A referida tentação se baseia no sucesso ou no fracasso que um indivíduo obtém ao empreender a tentativa de burlar o sistema do tabu, ao transgredir uma proibição. Ao conseguir êxito, incentiva os demais indivíduos a cometerem o mesmo ato, ao passo que, se fracassarem, inibe novas tentativas de cometimento do mesmo "erro".

\footnotetext{
${ }^{10}$ FREUD, Sigmund. Ibid. p.31

${ }^{11}$ FREUD, Sigmund. Ibid. p. 43

${ }^{12}$ FREUD, Sigmund. Ibid. p. 43 
Se uma só pessoa consegue gratificar o desejo reprimido, o mesmo desejo está fadado a ser despertado em todos os outros membros da comunidade. A fim de sofrear a tentação o transgressor invejado tem de ser despojado dos frutos de seu empreendimento e o castigo, não raramente, proporcionará àqueles que o executam uma oportunidade de cometer o mesmo ultraje, sob a aparência de um ato de expiação. Na verdade, este é um dos fundamentos do sistema penal humano e baseia-se, sem dúvida, corretamente, na pressuposição de que os impulsos proibidos encontram-se presentes tanto no criminoso como na comunidade que se vinga ${ }^{13}$.

Diante de tal exposição, torna-se evidente como a violação de certas proibições tabus constitui um perigo social que deve ser punido por toda a comunidade, com vistas a não sofrer danos maiores. $O$ risco da repetição seria capaz de dissolver toda a sociedade.

\section{O SISTEMA PENITENCIÁRIO}

Para evitar que ocorra uma espécie de "contaminação" de toda a sociedade, por tentação, em decorrência de um único indivíduo que se prestou a provocar a ira do tabu, é necessário que se tomem providências, como desprover o transgressor invejado dos frutos de seu empreendimento, bem como aplicar a ele um castigo, talvez sob a forma de privação da liberdade.

Uma das teorias da pena, denominada mista, afirma que seus objetivos são de punir e prevenir o crime simultaneamente. A punição, então, segue a mesma razão pela qual se acredita que a violação de um tabu pode ser corrigida por reparação ou expiação, que envolvem a renúncia a algum bem ou alguma liberdade. Desta maneira, a própria pena privativa de liberdade, adotada nos dias atuais sob a forma de prisões, seria um meio de penitência para os transgressores. Já a prevenção se daria ao se retirar um dos maiores bens que o indivíduo possui, que é a liberdade, diante dos olhos de toda a sociedade. Tal procedimento aumentaria ainda mais o medo, repressor do desejo, como também inibiria a tentação.

Ao se reconhecer que a renúncia a um bem ou a alguma liberdade pode reparar a violação de um tabu, percebe-se que a sua obediência significa em si mesma a renúncia de algo desejável. Desta forma, a proteção contra o proibido é a sua própria repetição,

\footnotetext{
${ }^{13}$ FREUD, Sigmund. Obra cit. p. 79

REVISTA DE ESTÉTICA E SEMIOTICA, BRASÍLIA, V. 3, N. 1 P. 42-61 JAN./JUN. 2013.
} 
quando se analisa o que é compreendido nas esferas do consciente e do inconsciente. Neste sentido,

(...) o impulso suprimido e o impulso que o suprime encontram satisfação simultânea e comum. O ato obsessivo é ostensivamente uma proteção contra $\mathrm{o}$ ato proibido, mas, na realidade, a nosso ver, trata-se de uma repetição dele $^{14}$.

Tal condição é o próprio fundamento sobre o qual o modelo Beccariano se baseia para propor a sua teoria em Dos Delitos e Das Penas. Tal teoria pressupõe que para que a pena seja justa, deve ser proporcional ao crime, com imposição realizada mediante processo regular com o intuito de se apurar a responsabilidade, para se aplicar uma sanção de forma mais humana. Da mesma forma, coloca uma concepção mais utilitarista à pena, ao tentar produzir no condenado o sentimento de arrependimento, impedindo que ele pudesse ofender outro cidadão, além de servir como exemplo para todos os membros da sociedade. Nesta tese, é evidenciada a dupla função da pena, que é a de punir bem como a de prevenir o crime.

A justificativa se refere à finalidade política da pena, em que a sociedade se obriga a incutir em seus partícipes o respeito e a obediência às leis. Sendo assim, a obediência e o respeito às leis significam em si a própria renúncia da parcela de liberdade que cada indivíduo.

No entanto, existe um sério problema estrutural no processo de purificação do crime, sob a forma de aprisionamento e privação da liberdade. Assim como a proibição do tabu e a obediência a ele encontram fundamento em comum, o cometimento de crime e o respeito ao ordenamento jurídico também se baseiam nas mesmas razões, tornando-se repetição de si mesmas. Nestes termos, diante da falta de assistência por parte do Estado, muitas vezes o cidadão se vê mitigado de uma série de direitos aos quais lhe deveriam ser assegurados.

Cada indivíduo, na concepção originária do contrato social, deveria ceder uma parcela de sua liberdade em troca de uma série de garantias. Desta forma, na consciência do delinqüente, isto é, daquele que resolve infringir as leis em prol de seu próprio benefício, entende-se no direito de violar a lei para alcançar o que almeja, ocasião em que o desejo prevalece sobre o medo.

\footnotetext{
${ }^{14}$ FREUD, Sigmund. Obra cit. p. 59. Freud, nesta passagem, considerou o termo ostensivamente como a parte consciente da mente, ao passo que realidade foi utilizado para se referir ao inconsciente.
} 
No caos ocasionado pela infração às leis penais, que tipificam os atos que são considerados crimes, pelos mesmos princípios que regem a transmissibilidade do tabu, o criminoso condenado se torna a personificação do próprio tabu, gerando um desconforto aos demais membros da sociedade, que tende a repeli-lo de seu meio. A prisão não é capaz de produzir eficácia suficiente que consiga retirar o estigma daquele que um dia esteve preso, por mais reabilitado que esteja de fato, para os olhos da sociedade que se vinga.

Para Cezar Roberto Bittencourt,

a ressocialização não pode ser conseguida numa instituição como a prisão. Os
centros de execução penal, as penitenciárias, tendem a converter-se num
microcosmos no qual se reproduzem e se agravam as graves contradições que
existem no sistema social exterior. (...) A pena privativa de liberdade não
ressocializa, ao contrário, estigmatiza o recluso, impedindo sua plena
reincorporação ao meio social. A prisão não cumpre uma função
ressocializadora. Serve como instrumento para a manutenção da estrutura
social de dominação ${ }^{15}$.

Neste sentido, o esforço ressocializador somente seria válido se visto como uma faculdade que se oferece ao delinqüente para que, livremente, ajude a si próprio. A transmissibilidade dos efeitos ocasionados pelo crime é maléfica tanto nos lados de fora das muralhas de aprisionamento, como também do lado de dentro. É preciso evitar a permanência de um criminoso em liberdade, com a finalidade de conter os seus reflexos para toda a sociedade. Da mesma forma, a troca de experiências dentro de um local como a prisão pode ocasionar um mal ainda mais profundo quando do retorno deste indivíduo à sociedade.

\section{A ARQUITETURA PRISIONAL}

Inicialmente, não havia uma política sistemática de aprisionamento, sendo, portanto, impossível identificar uma norma para projetos de estabelecimentos penais. A prisão não passava de um local com finalidade única de recolhimento, de modo a impedir que o preso fugisse enquanto aguardava a instrução criminal ou a execução da pena propriamente dita. Nesse sentido, uma grande variedade de edifícios não habitados

\footnotetext{
${ }^{15}$ Apud. BITTENCOURT, Cezar Roberto. O objetivo ressocializador na visão da Criminologia Crítica. RT 662, p.250.
} 
passou a ser utilizada para esse fim. Na época, muitas prisões se situavam nos subsolos de prédios públicos, por se tratar de um espaço não muito adequado para outros usos e por facilitar a prevenção contra fugas ${ }^{16}$.

Neste contexto, não havia separação dos presos por sexo, idade ou qualquer outro critério, sendo que não se dava a menor atenção ao bem-estar físico ou moral da pessoa humana. $\mathrm{O}$ amontoado de homens e mulheres nos mesmos locais tornava a promiscuidade inevitável.

Com tal realidade, não haveria sequer razão em difundir a idéia de purificação que a penitência da renúncia deveria realizar. A palavra "tabu" possui um sentido duplo, já que se refere simultaneamente ao que é "sagrado" e "impuro". Sendo assim, no contexto do crime e das penas, num período em que não havia um planejamento espacial para o local onde os criminosos eram aprisionados, indistintamente junto com leprosos e loucos, não haveria a menor condição de reformar o "impuro" em "sagrado" sob nenhuma hipótese.

O assunto, porém, começou a ter destaque e ser reformulado e pensado em períodos mais recentes, como, por exemplo, quando o inglês John Howard entendeu que a eficácia da pena estava ligada a melhores condições oferecidas ao preso durante sua execução, tais como uma boa alimentação, disciplina, eficaz manutenção dos estabelecimentos penitenciários pelo Estado, bem como prestação de assistência religiosa, como ponte para a reabilitação. Considerava também a importância do exercício do trabalho pelos criminosos como meio de torna-los cidadãos honestos.

Assim, o objetivo principal da arquitetura prisional é tentar, na medida do possível, respeitando-se a natureza do estabelecimento, prover condições favoráveis ao sujeito encarcerado para que se torne um cidadão correto. Lembrando, no entanto, que a execução da pena não se trata de privar o indivíduo de todos os seus direitos, mas tão somente de sua liberdade.

Na maior parte dos casos, o que se verifica nos estabelecimentos penais do país é o completo descaso por parte do Estado, o que gera uma série de privações no Sistema Penitenciário. Sendo assim, tanto o indivíduo preso tem uma série de problemas relacionados aos seus direitos sociais, que são garantidos por lei, como também uma gama de profissionais, como os da área de saúde, assistência social, como outros, deixam de ter condições mínimas para a realização de seus trabalhos junto ao Sistema Penitenciário.

\footnotetext{
${ }^{16}$ MADGE, John. Planejamento de prisões e reforma penal I. MIMEO.
} 
A falta de políticas sociais voltadas para assegurar que os direitos do preso e dos profissionais que trabalham no Sistema Penitenciário gera consequiências incomensuráveis, quando faz com que não se alcancem os propósitos aos quais a execução da pena se destina.

Para se ter idéia, o órgão competente para discutir assuntos relacionados ao Sistema Penitenciário é o Conselho Nacional de Políticas Criminais e Penitenciárias CNPCP. A Resolução nº 05/2006, por exemplo, que sugere metas e prioridades da política criminal e penitenciária coloca como objetivo principal, no que tange à construção, reforma, ampliação e aparelhamento de estabelecimentos penais, a geração de vagas e, somente em seguida, a construção de espaços e aquisição de equipamentos para a consecução de políticas públicas, como o Plano Nacional de Saúde no Sistema Penitenciário, por exemplo.

O planejamento de políticas sociais voltadas para a arquitetura prisional poderia reduzir custos, de modo a garantir que o financiamento delas fosse mais eficiente. Considerando que existe o Fundo Penitenciário Nacional - o FUNPEN - cujos recursos têm procedência, em parte, dos jogos de loteria legalizados, o que explicita a natureza das fontes de financiamento, em relação aos indicadores de direção do gasto social e a sua magnitude, não há explicação plausível para tantas falhas na manutenção dos direitos sociais do Sistema Penitenciário.

\section{ESTUDOS DE CASO}

É possível analisar a arquitetura, em seu aspecto sociológico, de um estabelecimento penitenciário tanto em sua escala de edificação fechada, quando observados os módulos de vivência isoladamente, onde se encontram as celas, os pátios, as oficinas, bem como em uma escala maior, quase que urbanística, quando verificados os sistemas abertos em que se integram os diferentes módulos e, ainda, as diferentes funções, onde acontecem todas as atividades, sejam dos presos, dos dirigentes e controladores, todas sob constante vigilância.

Com o intuito de verificar as influências da arquitetura prisional sobre a execução da pena, foi realizada a análise critica dos códigos arquitetônicos utilizados nos estabelecimentos penais, particularmente na Fazenda Papuda e na Colônia Penal Agrícola Heleno Fragoso, e as devidas interferências sobre a sua organização social. O foco principal de análise recaiu sobre o destinatário das funções do estabelecimento 
penal, que é o condenado. Sendo assim, foi analisada a influência que a arquitetura tem sobre os presos propriamente ditos e, eventualmente, sobre os demais usuários do local.

A metodologia adotada para a realização dos estudos de caso foi diversificada. No caso da Fazenda Papuda, houve entrevista com agentes penitenciários, advogados e sujeitos relacionados ao estabelecimento penal, além de visita pessoal realizada no dia 27 de abril de 2006, no Setor C, blocos F (que, na ocasião, estava ainda desocupado) e G, na companhia de um dos autores do projeto, engenheiro civil Nathaniel Peregrino Bloomfield, e técnicos do DEPEN. Já no caso da Colônia Penal Agrícola Heleno Fragoso, foi feita pesquisa em bancos de dados de entidades conveniadas.

O primeiro estudo de caso foi feito na Fazenda Papuda, estabelecimento penal de execução de penas privativas de liberdade em regimes aberto e semi-aberto no Distrito Federal. Trata-se de uma estrutura espacial complexa controlada pelo Estado, situada na Rodovia DF-465, km 02, distribuída em uma área de 1178 hectares, composta por módulos de vivência destinados aos presos, bem como de locais específicos para a realização de trabalhos administrativos dos entes dirigentes. O complexo penitenciário da Fazenda Papuda é composto por setores formados por quatro blocos (D, E, F e G), cujos módulos de vivência têm capacidade para 448 vagas. Cada dois blocos são supervisionados por um módulo administrativo, que funciona isoladamente um do outro.

Logo a partir da porta de entrada, controlada por comandos eletrônicos, por onde os presos chegam escoltados por policiais, se estende um longo corredor estreito e com o pé-direito bastante elevado que leva à central de controle que os encaminhará à sua destinação no estabelecimento. Esse corredor é o eixo do módulo, de onde se percebe a simetria de ambos os lados, e por onde o condenado passará em apenas duas ocasiões, na sua entrada e na sua saída. Trata-se de um ambiente mal iluminado e inibidor, ou até mesmo opressor, já que, por sua própria configuração, já tem um poder de diminuir o indivíduo que por ali passa.

O referido corredor dá acesso também ao advogado, que atende o cliente no parlatório, aos agentes, que, enquanto não estão em serviço, permanecem nos alojamentos, bem como aos médicos ou psicólogos ou profissionais da saúde que atendem nos consultórios. Faz parte do percurso da visita também, que espera a realização de sua identificação logo após o controle principal em salas de espera.

É importante ressaltar que o próprio sistema construtivo utilizado na edificação, com paredes de concreto de altíssima resistência forma uma gaiola de Faraday, uma 
blindagem elétrica, que é capaz de impedir a entrada de perturbações produzidas por campos elétricos e/ou eletromagnéticos externos. Neste sentido, ainda que houvesse alguma falha no sistema de revista por parte da segurança externa que autoriza a entrada de visitantes e algum aparelho de telefone celular, por exemplo, conseguisse chegar às mãos de um detento, não haveria possibilidades de comunicação, uma vez que não haveria qualquer vestígio de sinais de transmissão.

A partir do controle central, onde existe uma porta controlada eletronicamente por agentes, há uma bifurcação para os lados direito e esquerdo, onde as atividades de um lado do bloco se repetem perfeitamente do outro lado. Seguindo em frente, onde somente agentes penitenciários têm acesso liberado, há outro corredor que direciona ao posto de observação, que é uma guarita com capacidade para apenas uma pessoa, de onde se tem um amplo campo de visão. Nesse posto, existem instalações sanitárias para que o agente possa permanecer por longos períodos e nas janelas são aplicadas películas insulfilm com o propósito de evitar que o preso que estiver no pátio de banho de sol veja se existe ou não alguém vigiando. Outra peculiaridade que se observa é o fato de não haver iluminação artificial dentro da guarita. Tal fato se explica pelo fato de haver a intenção de que o agente permaneça sempre alerta e não haja a possibilidade de ele se distrair realizando leituras, por exemplo. Apenas por essa breve descrição, já se pode perceber uma influência tremenda da arquitetura sobre os usuários do estabelecimento. Trata-se de um efeito semiótico permanente, em que as coisas podem parecer o que de fato não são. Tanto os presos quanto os agentes tendem a se sentirem permanentemente vigiados, ainda que não estejam, de fato, sendo observados por ninguém.

Os quartos de encontros íntimos são dispostos de modo a comportar uma cama de casal e um banheiro. É um local cuja manutenção é feita por um preso considerado de bom comportamento, que, geralmente, realiza a limpeza. Apesar de se analisado ortodoxamente, tratar-se de um quarto aparentemente "normal", uma suíte, mais precisamente, existe uma pressão psicológica ocasionada pela ciência da observação constante, pelo constrangimento da vistoria e da revista realizada antes e depois do uso dos quartos e, além de tudo, do tempo marcado para a realização dos encontros íntimos, que dura em torno de vinte minutos.

Do outro lado, contíguo ao controle secundário, que é mantido num patamar mais elevado, até mesmo pela mensagem implícita de hierarquia, fica o acesso ao pátio de banho de sol, onde existe uma área coberta, em que se encontram as mesas do refeitório, os tanques (de lavagem de roupa) e os banheiros, e outra descoberta. Nessa 
área, há vigilância constante de dois pontos distintos: do agente localizado no controle, e também daquele que fica no posto de observação, com quem mantém contato visual.

Os pilares que sustentam a área coberta são de seção triangular exatamente para coibir as tentativas de fuga. Apesar de não evitar que o preso tente escalar, caso o faça, seus braços ficarão marcados pela fricção ocasionada contra as quinas dos pilares, no esforço de se sustentar, o que facilitará, posteriormente, a identificação do preso “rebelde”. É verificável, nessa situação, o poder que a disposição das funções na organização espacial consegue moldar comportamentos. Pelo simples fato de se construir um elemento estrutural em seção diferenciada, já se proporciona uma alteração psicológica dos usuários do local.

Nesse mesmo pátio, ocorrem as visitas familiares, sendo, portanto, o local onde os detentos recebem seus parentes e amigos. sob vigilância constante, é gerado o efeito panóptico idealizado por Bentham. Tal efeito é ainda maximizado ao se perceber que, apesar de os dois lados simétricos não se comunicarem entre si, pela ótica do preso, os agentes que fazem a vigilância estarem em uma triangulação de comunicação bastante delimitada e eficiente.

Mais adiante, após outras portas controladas eletronicamente, ficam os corredores de acesso às celas. Cada cela comporta um total de oito presos, sendo as acomodações representadas por quatro beliches e aparelho sanitário, com uma torneira alta, que funciona como chuveiro, e outra baixa. São locais altamente insalubres, considerando que a ventilação e iluminação natural ocorrem por uma única parede, ao lado do "banheiro", que, por sua vez, dá acesso ao corredor, que fica contíguo a um poço de ventilação.

Sendo assim, a prisão, com todos esses seus objetivos implícitos de corrigir, punir, alterar e codificar comportamentos tem uma função extremamente complexa, em que a arquitetura, definitivamente, possui sua inegável influência.

É bastante funcional a distribuição dos espaços na Fazenda Papuda, como estabelecimento penal. Se a análise feita se limitasse meramente nas funções que deveriam acontecer, esta seria demasiadamente facilitada. No entanto, sabe-se que o problema é de uma complexidade muito maior.

Considerando que existe um binômio que molda as escolhas para um projeto de estabelecimento penal que gira em torno da segurança e da ressocialização, o planejamento acaba pendendo para um dos lados, já que os dois pólos da questão são diametralmente opostos. No caso da Papuda, a escolha recaiu sobre a segurança. Sob 
essa perspectiva, o estabelecimento se comporta muito bem, uma vez que a vigilância constante inibe as tentativas de fuga e rebeliões. O comportamento dos detentos, nesse aspecto, é alterado positivamente de modo a funcionar nos moldes do esperado quando do planejamento espacial.

No entanto, quando o enfoque é a ressocialização do condenado, o estabelecimento deixa a desejar. Por se tratar de um ambiente em que se priva o contato entre presos e, logicamente, com a sociedade em geral, o propósito citado já fica mitigado. Além do mais, pode-se perceber a dificuldade de promover qualquer tipo de tentativa de reinserção social, já que se dá a impressão de ser renegado, inferior, já que há essa relação de hierarquia em que os agentes são superiores e a eles deve ser dispensado respeito e submissão.

Além do mais, as próprias paredes e corredores fazem o seu devido papel de diminuir ainda mais o indivíduo, dando a ele a sensação de ser um animal enjaulado. Até as visitas, que, em tese, seriam o contato com o mundo exterior se sentem oprimidas pela dimensão da prisão e seus reflexos tanto sintáticos quanto semânticos.

A Colônia Penal Agrícola Heleno Fragoso, por sua vez, fica localizada no complexo penitenciário de Americano, em Santa Isabel do Pará, a 50 quilômetros de Belém. É um local onde se tem conseguido êxito em seu propósito de ressocialização dos detentos, oferecendo trabalho e ensinando novos ofícios.

Devido a uma parceria entre a Empresa Brasileira de Pesquisa Agropecuária Embrapa - e a Superintendência do Sistema Penal do Estado do Pará - Susipe, foi oficializado um convênio em janeiro de 1998, relacionado à criação de búfalos e ao beneficiamento do leite, em que os presos aprendem técnicas de criação de búfalos leiteiros, inseminação artificial e industrialização do leite. Foram cedidos, em regime de comodato, 30 matrizes e um reprodutor pela Embrapa. À Susipe, coube o compromisso de devolver à instituição de pesquisa, anualmente, cinco fêmeas.

Os presos, por meio deste convênio, aprendem a tratar dos animais, ordenhar, acompanham os partos e fazem inseminação artificial. Internos trabalham no criatório de búfalos e a cada três dias de jornada, segundo o benefício da remição, convertem um na redução de suas penas. Além disso, ganham uma ajuda de custo, sendo que uma parte dela vai para uma caderneta de poupança, que será liberada ao final da pena.

Segundo Amaury Bendahan, engenheiro agrônomo responsável pelo projeto "Produtos Liberdade", é visível a mudança no comportamento dos detentos que interagem com os animais. Seu depoimento descreve que 
além de mais calmos, eles passam a ter responsabilidades decorrentes das atividades da criação, como alimentação, inseminação e ordenha. Cumprem um cronograma que lhes dá, em alguns casos, a primeira oportunidade de desenvolver um trabalho com resultado positivo, palpável, aumentando sua auto-estima, muito depreciada pela condição em que se encontram.

Além de tantos resultados positivos, no âmbito da produtividade dentre os presos e seu aprendizado em novas técnicas, a venda de queijos, iogurtes, doce de leite, manteiga e requeijão, decorrentes do projeto, gera uma renda anual de $\mathrm{R} \$ 20$ mil, ou $\mathrm{R} \$$ 1,6 mil mensais.

Em outro aspecto, existe também um convênio celebrado entre a Susipe e o Serviço Nacional de Aprendizagem Industrial (SENAI). Por meio dele, professores e equipamentos foram levados à Colônia Penal para que pudessem ser ministrados cursos direcionados ao setor de construção civil dentro da própria casa penal. Os objetivos do convênio, mais uma vez, é colaborar na ressocialização do apenado, com a oportunidade de aprender um ofício para, depois, ter a chance de trabalhar e conquistar o seu sustento de forma digna.

Além dessas atividades mais especializadas, os internos da Colônia também desenvolvem outras, como floricultura, cultivo de hortaliças, produção de frutas, além da criação de porcos, patos, peixes, além da já citada criação de búfalos, entre outras.

Levando em consideração o fator economia estatal, a Colônia Penal Agrícola é uma excelente opção para a execução das penas não somente devido às maiores possibilidades de ressocialização, mas também devido às melhores condições de se criar um estabelecimento auto-suficiente, segundo as concepções de verticalização e integração da produção.

Para que os convênios mencionados pudessem ser celebrados, de maneira que aos detentos fosse possível permanecer dentro do próprio estabelecimento penal, aprendendo um ofício, é lógico que existia a necessidade de se destinar um espaço apropriado para tais atividades. Assim, é evidente que a arquitetura local favoreceu a inclusão de novas atividades, destinando, portanto, espaço adequado para seu desenvolvimento.

Neste contexto, a Colônia Heleno Fragoso voltou-se para a ressocialização do apenado em detrimento da segurança. Assim, em termos de sistemas construtivos, optou pela utilização de materiais mais econômicos e de menor resistência, como a própria 


\section{ÉRIKA WEN YIH SUN}

alvenaria no lugar do concreto. Ao mesmo tempo, porém, não deixou de adotar medidas de segurança padronizadas pelas regras para estabelecimentos penais, como a construção de guaritas e postos de vigilância.

Apesar de se tratar de um estabelecimento em que foi priorizado o objetivo da ressocialização, tomando menos cautelas e precauções com a segurança, em termos de arquitetura, as pesquisas sobre o local demonstram que os índices de fuga e reincidência são perto de zero. O comportamento do apenado se torna mais dócil e o seu perfil social é mais facilmente moldado conforme padrões pré-estabelecidos, já que o detento é tratado de forma digna e a ele é oportunizada uma possibilidade de aprendizado e reinserção na sociedade. Desta forma, a segurança é conseguida de forma indireta, como conseqüência dos próprios princípios adotados para a ressocialização.

\section{CONCLUSÕES}

A arquitetura, sob o ponto de vista explicitado no presente trabalho, é de importância inegável para a execução da pena em seus propósitos de punir e corrigir, simultaneamente. Mas é necessário reconhecer as limitações dentro dessas perspectivas, uma vez que se tratam de funções eminentemente paradoxais entre si. A influência sobre o comportamento das pessoas que vivem em estabelecimentos penais é visível, porém depende de política pública que a defina. Neste sentido, sabe-se que é eficiente, uma vez que causa efeitos. Cabe, no entanto, analisar a eficácia de tais efeitos sobre o comportamento das pessoas, na intenção de perceber se eles são positivos ou negativos.

Assim, é perceptível sensivelmente que a arquitetura de um estabelecimento de natureza penal promove influências consideráveis à organização social, bem como às consequiências resultantes quanto às garantias dos direitos sociais. Cabe, portanto, o estabelecimento de critérios específicos para garantir uma análise objetiva quanto ao bom ou mau desempenho.

De um modo geral, a arquitetura prisional, seguindo as políticas públicas (ou a falta delas), tende a priorizar a segurança como objetivo primordial da execução da pena, deixando como plano secundário a finalidade da ressocialização. Tal opção se justifica pelo fato de que a privação da liberdade é a punição ao apenado pela infração cometida, sendo, ainda, fundamental a retribuição do mal injusto cometido em desfavor da sociedade.

No entanto, a estratégia mais adequada para se conseguir os melhores resultados parece estar na adoção de vias adjacentes. Isso não significa deixar os princípios de 
segurança à margem de planejamento, mas que a ressocialização seja o objetivo principal a ser buscado.

É importante que haja a promoção de meios em que o apenado possa ser útil, produzindo algo para si mesmo e, dentro das possibilidades, para a sociedade como um todo. O planejamento do espaço que permita o desenvolvimento de atividades de trabalho e de lazer é, talvez, a forma em que a execução da pena se mostre mais próxima do alcance de seus objetivos de punição e correção.

À primeira vista, pode parecer que oferecer condições dignas de vida, atendendo inclusive a requisitos de Direitos Humanos, não seja punir o indivíduo que cometeu um crime. A punição, segundo entendimento do senso comum, deve ser severa. Entretanto, deve-se lembrar de que o simples fato de se retirar a liberdade já é uma perda incomensurável na vida de um ser social, como é o caso do homem. Além da limitação do direito de livre locomoção, a privação do convívio com pessoas como amigos e familiares, em detrimento de outras que, muitas vezes, são até mesmo desagradáveis, a imposição de regras e horários já se tornam meios de condenar o sujeito pelo mal causado à sociedade.

Sendo assim, alcançados os objetivos de ressocialização do apenado, fornecendo a ele subsídios para que o retorno ao mundo extramuros seja uma transição mais homogênea, a segurança é gerada como conseqüência. Os meios utilizados para atribuir valores sociais padronizados aos presos geram um comportamento mais dócil, o que permite tratamentos menos agressivos e menor investimentos em equipamentos de segurança, bem como em pessoal e treinamento.

Como resultado, não só é reduzido o custo de construção e manutenção do estabelecimento penal em si, reduzindo, assim, os gastos do Estado, como também é garantida uma maior possibilidade de retorno bem sucedido do apenado à sociedade, de modo que não haja reincidência que o faça voltar à prisão. Além disso, sendo proporcionado um ambiente razoável de convivência, não há motivos também para tentativas de fuga, sobretudo devido ao fato de que tal comportamento ensejaria em uma regressão de regime de pena, dependendo do caso em concreto.

Desta forma, é possível que o modo em que a execução da pena vem sendo, há muito tempo, predominantemente aplicada tenha sido equivocado, ao se buscar a finalidade de punição em primeiro lugar. Talvez seja o caso de se pensar que nem sempre as metas a serem alcançadas devem ser buscadas pelos caminhos mais óbvios e evidentes. Muitas vezes, é necessário se tomar as vias adjacentes para o alcance delas. 
ÉRIKA WEN YIH SUN

A LEP busca estabelecer uma série de determinações a serem seguidas, não só em relação aos regimes de execução da pena, mas também aos benefícios, às concessões e privações impostas ao apenado. Dentre todos os preceitos encontrados no diploma legal mencionado, estão regras de arquitetura, num âmbito generalizado, que devem ser seguidos.

Neste sentido, é preciso verificar que as maiores falhas encontradas na arquitetura de estabelecimentos penais não estão na legislação aplicada. Muito pelo contrário, a LEP, como norma regulamentadora da execução da pena, trata muito bem do assunto a que se propõe. No entanto, os esforços deveriam se voltar mais para a reforma do Sistema Penitenciário como um todo, de modo a se tentar colocar em prática o que já se preceitua na teoria explicitada em um dever-ser idealizado em lei. 


\section{REFERÊNCIAS BIBLIOGRÁFICAS}

BECCARIA, Cesare. Dos delitos e das penas. Tradução: Deocleciano Torrieri Guimarães. São Paulo: Rideel, 2003.

FAGNANI, Eduardo. Avaliação do ponto de vista do gasto e financiamento das políticas públicas. MIMEO.

FOUCAULT, Michel. Vigiar e Punir: nascimento da prisão. Tradução de Raquel Ramalhete. $27^{\mathrm{a}}$ edição. Petrópolis: Vozes, 1987.

FOUCAULT, Michel. Estratégia, poder-saber. Organização e seleção de textos: Manoel Barros da Motta; tradução: Vera Lúcia Avellar Ribeiro. Rio de Janeiro: Forense Universitária, 2003.

FREUD, Sigmund. Totem e Tabu. Rio de Janeiro: Imago Ed, 2005.

GOFFMAN, Erving. Manicômios, prisões e conventos. São Paulo: Perspectiva, 2005.

GOMES JUNIOR, Newton N. Pobreza, desnutrição e segurança alimentar: tentando novo diálogo a partir do conceito de necessidades humanas básicas in Ser Social: Revista do Programa de Pós-Graduação em Política Social / Universidade de Brasília. Departamento de Serviço Social - v.1, n.1 (1ºmestre/1998). Brasília, SER Social UnB, 1998.

MADGE, John. Antecedentes das atuais prisões. MIMEO.

MIRABETE, Julio Fabbrini. Execução Penal: comentários à Lei $n^{\circ}$ 7.210, de 11-71984. $11^{a}$ edição - Revista e Atualizada. São Paulo: Atlas, 2004.

MIRABETE, Julio Fabbrini. Manual de Direito Penal - Volume I (Parte Geral). 19 edição. São Paulo: Atlas, 2003.

MULLER, Pierre \& SUREL, Yves. L'Analyse des politiques publiques. Paris: Editions Montchrestien, 1998.

NIETZSCHE, FRIEDRICH. Fragmentos do Espólio. Brasília: Ed. Universidade de Brasília, 2004. Prefácio de Flávio R. Kothe.

PEREIRA, Potyara A.P. Políticas públicas e necessidades humanas com enfoque no gênero. MIMEO.

PULS, Mauricio. Arquitetura e Filosofia. São Paulo: Annablume, 2006. 
ÉRIKA WEN YIH SUN

SANTOS, Cíntia Helena dos. Por um tratamento penal possível: contribuições da Psicanálise e da Redução de Danos. Monografia apresentada à Pró-Reitoria de Pesquisa e Pós-Graduação da Universidade Federal do Paraná, como requisito à conclusão do Curso de Especialização em Modalidades de Tratamento Penal e Gestão Prisional. Curitiba: 2003. 